\begin{tabular}{|c|c|c|}
\hline 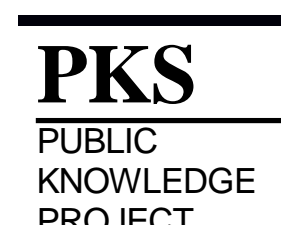 & $\begin{array}{l}\text { REVISTA DE GEOGRAFIA } \\
\text { (RECIFE) } \\
\text { http://www.revistaufpe.br/revistageografial }\end{array}$ & 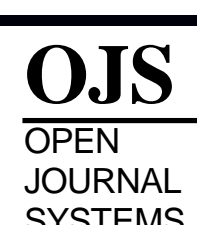 \\
\hline
\end{tabular}

\title{
A REGIONALIZAÇÃO COMO EXPRESSÃO DO LIVRE ARBÍTRIO NASS INSTITUCIONALIZAÇÕES DAS REGIÕES METROPOLITANAS DO ESTADO DE ALAGOAS
}

\author{
Paulo Rogerio de Freitas Silva ${ }^{1}$ \\ ${ }^{1}$ Instituto de Geografia, Desenvolvimento e Meio Ambiente da UFAL. Email: paulgeografia@gmail.com
}

Artigo recebido em 08/05/2017 e aceito em 18/05/2017

\begin{abstract}
RESUMO
Essa proposta de pesquisa aponta, inicialmente, a busca de apresentar e analisar a institucionalização das regiões metropolitanas do Estado de Alagoas, na perspectiva de relacionar com os conceitos de região, região metropolitana, metrópole, conurbação e as diferentes formas de operacionalização que culminam com uma regionalização. Regionalização utilizada na expectativa de instrumento ou estratégia de ação para a complementação de uma política de desenvolvimento regional e urbano. O percurso metodológico propõe catalogar os conceitos citados, correlacionando com a institucionalização oficial das regiões metropolitanas, através de investigação das Leis Complementares que criaram essas regiões; de apreciação do Estatuto da Metrópole; relacionando também com os conceitos da ciência geográfica, arguindo se essas regiões institucionalizadas possuem as complexidades que possam lhe proporcionar essa nomenclatura. Essa proposta de debatermos as regiões metropolitanas institucionalizadas em Alagoas, considerando esse cenário de nove propostas de regionalização, se justifica a partir da afirmativa de alguns estudiosos de que, muitas, no Brasil, de fato, não passam de aglomerados, pois, não possuem nenhuma complexidade, nenhuma área de influência que justifique o status de metrópoles. Diante dessas questões, se explica nossa empreitada na busca de entender os arranjos que se planejam para agruparem os municípios ou as cidades em suas áreas de influências, se aproximando de propostas que buscam aplicar modelos de desenvolvimento, para avaliarmos as instituídas regiões metropolitanas do Estado das Alagoas.
\end{abstract}

Palavras-chaves: Alagoas; institucionalização; metrópole; região

\section{REGIONALIZATION AS AN EXPRESSION OF FREE WILL IN THE INSTITUTIONALIZATION OF METROPOLITAN REGIONS IN THE STATE OF ALAGOAS}

\begin{abstract}
This research proposal initially seeks to present and analyze the institutionalization of metropolitan regions in the State of Alagoas, aiming at building a relation between this process and the concepts of region, metropolitan region, metropolis, conurbation and the different operative procedures that ultimately lead to a regionalization of some sort. Regionalization is often used as an expectation tool or strategy of action to complement a regional and urban development policy. The chosen methodological pathway proposes to analyze the above mentioned concepts and correlate them to the official institutionalization of metropolitan regions, by means of investigating the complementary laws that created those regions; the Statute of the Metropolis, and correlating these documents with the concepts that emanate from the geographical Science, thus enquiring whether these institutionalized metropolitan regions possess the necessary degree of complexity to be addressed as such. This proposal of debating the institutionalized metropolitan regions of Alagoas, considering the current scenario with nine metropolization bids, is justified based on the statement of some scholars who believe that several of such


metropolises in Brazil are nothing more than agglomerations, since they lack both the complexity and the influence zone that could render them the metropolis status. In face of these issues, we explain the present effort in seeking to understand the planning arrangements involved in the grouping of municipalities or cities within their influence areas, thus coming closer to proposals that aim to apply development models in order to assess the institutionalized Metropolitan regions at the State of Alagoas.

Keywords: State of Alagoas; Institutionalization; metropolis; region. 


\section{INTRODUÇÃO}

Com a sistematização da geografia esta buscou estabelecer parâmetros que definissem regiões, utilizando variáveis ou elementos que individualizassem o espaço terrestre. Ao longo dos paradigmas dessa ciência, as características naturais, culturais, econômicas, além do estímulo ao planejamento pelo Estado, estabeleceram as regionalizações, fundamentando um percurso teórico-metodológico para a afirmação desse conhecimento. Há de se considerar, como destaca Gomes (2005), que é necessário reconhecer “(...) a existência da noção de região em outros domínios, que não os da ciência e, o mais importante, reconhecendo, ao mesmo tempo, a variedade de seu emprego no âmbito da própria ciência e particularmente na geografia."

Ao mesmo tempo, é importante destacar que a regionalização do mundo principiou no Império Romano, como uma forma de se definir extensões territoriais, que ainda que fossem autônomas, eram subordinadas a Roma, numa perspectiva política que posiciona a organização espacial num caráter conceitual da formação territorial.

Nessa conjuntura, baseados em Corrêa (2001), ao se debruçar sobre o estudo de região, que:

O termo, contudo, passou a designar uma dada porção da superfície terrestre que, por um critério ou outro, era reconhecida como diferente de uma outra porção. O termo região faz parte da linguagem do homem comum. No entanto é um conceitochave para os geógrafos e tem sido empregado também por todos os cientistas sociais quando incorporam em suas pesquisas a dimensão espacial.

Sendo assim, falar em região, tal como destaca Costa (2010), “(...) é também, concomitantemente, envolver-se com os diversos processos e/ou métodos de regionalização (...). (...) desde a visão mais racionalista que percebe a região como mero construto do nosso intelecto, (...) até abordagens mais realistas, em torno de fenômenos socioespaciais efetivos (...). $"$

Nesse ínterim, consideramos, ao se referir a fenômenos socioespaciais efetivos destacados por Costa (2010), que os mesmos possibilitam a individualização de uma área, de acordo com visões e abordagens diversas, porem os limites burocráticos, tal como de um município ou de uma cidade, não comportam atualmente, a influência dos mesmos ou os elementos que os compõem, exigindo novas territorialidades, tal como destaca Villaça (2003), ao registrar que:

Já é um lugar-comum a colocação de que ultimamente um município não é mais a unidade territorial adequada ao enquadramento territorial da absoluta maioria dos processos sociais e econômicos. Mantenhamo-nos no caso das cidades... as regiões 
metropolitanas, as conurbações, as aglomerações urbanas e outros nomes que andam criando, seriam os enquadramentos territoriais mais adequados. Hoje, praticamente qualquer cidade média, pelo menos no sul do Brasil, já transbordou seus limites municipais.

Diante dessas questões, se justifica nossa empreitada na busca de entender os arranjos que se planejam para agruparem os municípios ou as cidades em suas áreas de influências, se aproximando da proposta do título do livro de Gonçalves; Brandão; Galvão (2003), "Regiões e cidades, cidades nas regiões: o desafio urbano regional", para avaliarmos as instituídas regiões metropolitanas do Estado das Alagoas no que se referem ao transbordamento da influência e/ou as relações entre os municípios e cidades, que as compõem, expressando distintas escalas de um processo.

Esses arranjos, que Souza (2003) define como, “(...) um minissistema urbano em escala local, polarizado, esse sistema, por uma cidade principal, que abriga o núcleo metropolitano", formaliza as regiões metropolitanas nas suas diversas nuances.

Arranjos, que também podem ser definidos como, aglomerações urbanas e como RIDE - região integrada de desenvolvimento econômico, formalizando uma estrutura organizacional posta em prática.

Essas estruturas, ao ultrapassarem os limites territoriais de um município ou de uma cidade, alcançam outros, em muitos casos formalizando o processo de conurbação, que para Souza (2003),

(...) significa o resultado do "encontro" de dois ou mais tecidos urbanos em expansão. Nesse caso, mesmo que os limites formais entre dois municípios permaneçam, não há mais descontinuidade de tecido urbano edificado entre eles, pois os seus núcleos urbanos principais cresceram até se tocarem e formarem uma verdadeira coalescência, uma mancha única de espaço construído.

Esse processo de conurbação formaliza, em muitos casos, mas não obrigatoriamente, o que o IBGE (2000), define como regiões metropolitanas, que, “(...) são constituídas por agrupamentos de municípios limítrofes, com o objetivo de integrar a organização, o planejamento e a execução de funções públicas de interesse comum. " Assim como também, formaliza outros tipos de arranjos diversos, que definimos como regiões.

Regiões essas, formadas a partir de municípios, que são unidades autônomas de menor hierarquia dentro da organização político-administrativa do Brasil e de cidades que são localidades onde está sediada a Prefeitura Municipal (IBGE, 2010). 
Fazendo uma conjunção do que estabelecem os conceitos de conurbação, região metropolitana, município e cidade, nos reportamos a Rodrigues (2006), que assim analisa a formação das regiões metropolitanas do Brasil na década de 1970,

Historicamente, pensar em gestão metropolitana implica analisar a atuação do Estado. Dessa forma, a instituição das regiões metropolitanas na década de 1970 tinha como pressuposto a análise das influências que algumas cidades exerciam sobre a dinâmica econômica e política de uma região ou mesmo de todo o país.

Por isso a formação das nove pioneiras regiões metropolitanas do Brasil ocorreu onde a urbanização materializava-se no espaço de forma mais intensa provocando, inclusive, a conurbação das áreas urbanas dos municípios limítrofes. Ou seja, do ponto de vista territorial, as regiões metropolitanas se caracterizavam como produto do processo de urbanização da época.

Nessa perspectiva, improvisamos um elo entre metrópole e região metropolitana, baseados em Lencioni (2006), pois,

(...) o conceito de metrópole é polissêmico. Hoje em dia, sejam quais forem as interpretações do que vem a ser uma metrópole, alguns pontos são comuns. Um desses é a ideia de que a metrópole se constitui numa forma urbana de tamanho expressivo, quer relativo ao número de sua população, quer em relação à sua extensão territorial; um segundo é que a metrópole tem uma gama diversa de atividades econômicas, destacando-se a concentração de serviços de ordem superior; um terceiro é que ela consiste num locus privilegiado de inovação; um quarto é que constitui um ponto de grande densidade de emissão e recepção dos fluxos de informação e comunicação, e um quinto é que a metrópole se constitui em um nó significativo de redes, sejam de transporte, informação, comunicação, cultura, inovação, consumo, poder ou, mesmo, de cidades.

Para Moraes (2006),

A funcionalidade da metrópole exprime cada vez mais sua articulação com as economias nacionais (conforme acentua-se a globalização). Cada metrópole expressa seus vínculos funcionalmente (no "circuito superior", para usar outra conceituação de Milton Santos), e na disfuncionalidade própria da sociabilidade capitalista nos "circuitos inferiores" em um quadro em que a disfuncionalidade se acentuam quanto mais nos aprofundamos no mundo periférico. A extrema periferia (ali onde a modernidade é mais restrita) não tem metrópoles.

Sendo assim, contém a periferia, onde a modernidade é mais restrita, regiões metropolitanas?. 


\section{UM BREVE HISTÓRICO SOBRE A CRIAÇÃO DAS REGIÕES METROPOLITANAS NO BRASIL}

Buscando construir um histórico, acerca da institucionalização das regiões metropolitanas no Brasil, Lencioni (2006), assinala que, oito regiões metropolitanas brasileiras foram instituídas em 1973, entre elas, São Paulo, Belo Horizonte, Curitiba, Porto Alegre, Salvador, Recife, Fortaleza e Belém, porém, o Rio de Janeiro somente em 1974, após a fusão dos estados da Guanabara e do Rio de Janeiro. Após a Constituição Federal de 1988, dezessete novas regiões metropolitanas foram estabelecidas, sendo elas, Natal (1997), Grande São Luiz (1998) e Maceió (1998) no Nordeste brasileiro; a Grande Vitória (1995), Baixada Santista (1996), Campinas (2000), além do Vale do Aço, cujo núcleo é Ipatinga em Minas Gerias (1998), todas no Sudeste; no Centro-Oeste foi instituída, a região metropolitana de Goiânia (1999) e a RIDE (Região Integrada de Desenvolvimento Econômico) do Distrito Federal e seu entorno (2000); Londrina (1998), Maringá (1998), Florianópolis (1998), Norte/Nordeste Catarinense (1998), Vale do Itajaí (1998), RM Carbonífera (2002), RM Foz do Rio Itajaí, RM de Tubarão (2002), no sul do Brasil.

Até o ano de 1994, ainda se mantinham as nove regiões metropolitanas iniciais, instituídas em 1973 e 1974, mas, somente a partir do ano de 1995 é que ocorreu um aumento quantitativo das mesmas, assim como da institucionalização das regiões integradas de desenvolvimento econômico, alcançando, o total de 36 aglomerações atuais, segundo dados do IBGE (2010).

O aumento no número das regiões metropolitanas, conforme aponta Rodrigues, (2006), ocorreu quando a Constituição de 1988 passou para os Estados a competência de criação de novas regiões metropolitanas no Brasil com o argumento da descentralização administrativa. A autora acrescenta que historicamente, o momento influenciou a necessidade de reestruturação da competência e argumentação de criação de regiões metropolitanas no País.

Acrescentamos baseados no IBGE (2000), que as unidades da federação buscando solucionar problemas de gestão do território estadual, definiram suas regiões metropolitanas.

Ressaltamos que, muitas dessas novas Regiões Metropolitanas e dessas Regiões Integradas de Desenvolvimento Econômico, são motivos de debates entre os especialistas que se dedicam ao estudo das mesmas, principalmente no que se alude aos critérios empregados na metodologia de concepção dessas unidades político-administrativas, com evidência ao 
evento de muitas das novas regiões metropolitanas não agruparem ainda, sequer, um contingente demográfico significativo que explique a sua institucionalização. Pode-se destacar também a formação de fato de regiões conurbadas ou próximas desse fenômeno que possa ser considerada uma região metropolitana ou apenas uma aglomeração urbana.

Nessa perspectiva de debatermos critérios empregados na definição de Região Metropolitana e Região Integrada de Desenvolvimento Econômico, ao considerarmos esse cenário de 39 propostas de regionalização, recorremos a Souza (2003), que ressalta que, muitas, no Brasil, de fato, não passam de aglomerados, pois, não possuem nem uma complexidade, nem uma área de influência que justifique o status de metrópoles.

Conforme aponta Souza (2003),

\begin{abstract}
A razão desse reconhecimento formal das metrópoles era dupla: explicitamente, tornar mais racional, sob o ângulo econômico, a prestação dos chamados serviços de interesse comum, isto é, serviços que interessam a mais de um município e que podem ser mais inteligentemente oferecidos por meio de uma gestão integrada, como a destinação do lixo, o abastecimento de água, a proteção ambiental e outros mais; (...) havia, também, um objetivo de "geopolítica interna", que dizia respeito ao interesse instalado pelo golpe militar de 1964 em intervir mais facilmente nesses que eram os espaços-chave da vida econômica e político-social brasileira (...).
\end{abstract}

Diante essas discussões, como entender as nove instituídas regiões metropolitanas em Alagoas, considerando a realidade das mesmas que justifique essa condição?

Nessas circunstâncias, inicialmente nos reportamos a Lei $\mathrm{n}^{\circ} 13.089$ de 12 de janeiro de 2015, que instituiu o Estatuto da Metrópole, alterando a Lei no 10.257 de 10 de julho de 2001. Esta Lei estabelece diretrizes gerais para o planejamento, a gestão e a execução das funções públicas de interesse comum em regiões metropolitanas e em aglomerações urbanas instituídas pelos Estados, normas gerais sobre o plano de desenvolvimento urbano integrado e outros instrumentos de governança interfederativa e critérios para o apoio da União a ações que envolvam governança interfederativa no campo do desenvolvimento urbano com base nos incisos XX do art. 21, IX, do art. 23 e I do art. 24 no $\S 3^{\circ}$ do art. 25 e no art. 182 da Constituição Federal.

Para os efeitos dessa Lei, consideram-se:

- Aglomeração urbana: unidade territorial urbana constituída pelo agrupamento de 2 (dois) ou mais Municípios limítrofes, caracterizados por complementaridade funcional e integração das dinâmicas geográficas, ambientais, políticas e socioeconômicas.

- Por outro lado, o Estatuto da Metrópole define a metrópole como "espaço urbano com continuidade territorial que, em razão de sua população e relevância política e socioeconômica, tem influência nacional ou sobre uma região que configure, no 
mínimo, a área de influência de uma capital regional, conforme os critérios adotados pela Fundação Instituto Brasileiro de Geografia e Estatística - IBGE.”

- A região metropolitana seria uma aglomeração urbana que configure uma metrópole.

Os critérios para a delimitação da região de influência de uma capital regional, previsto nos inciso V do caput do artigo 2 do Estatuto da Metrópole, considera os bens e serviços fornecidos pela cidade à região, abrangendo produtos industriais, educação, saúde, serviços bancários, comercio, empregos e outros itens pertinentes.

Lencioni (2006), ao se referir as capitais estaduais, esclarece que:

\begin{abstract}
A condição de capital cria maiores possibilidades de as metrópoles consolidarem o processo de metropolização que vem ocorrendo, pois, como capitais, polarizam a aglomeração urbana, constituindo nó importante de redes, bem como concentrando toda sorte de serviços mais avançados e de serviços públicos importantes para o capital, e, também, os fluxos de informação, comunicação e as universidades. É o caso de Natal, São Luiz e Maceió, no Norte; Grande Vitória no Sudeste; Goiânia e Brasília no Centro-Oeste, e Florianópolis, no Sul.
\end{abstract}

Sendo assim, a condição de uma cidade como capital de um estado, lhe posiciona favoravelmente a categoria de centro regional, face as variáveis, elencadas por Lencioni (2006), e consequentemente alcança a categoria de região metropolitana, constituída por uma aglomeração urbana com a condição de metrópole, conforme reza o Estatuto da Metrópole.

No que se refere especificamente ao Nordeste brasileiro, elencamos as instituídas regiões metropolitanas, conforme o IBGE, (2010), ano de criação e suas respectivas populações, considerando Recife, Fortaleza e Salvador, como metrópoles pioneiras, São Luiz, Natal, João Pessoa, Maceió e Aracaju, como capitais de estado, obtendo a condição de regiões metropolitanas. Campina Grande, Cariri, Agreste e Sudoeste Maranhense, como regiões metropolitanas instituídas a partir do ano de 2005.

No que se refere a Teresina, capital do estado do Piauí, o IBGE a apresenta como uma RIDE denominada de Grande Teresina, tendo sido criada pela Lei Complementar $n^{\circ} 112$, de 19 de setembro de 2001, e instituída pelo Decreto $\mathrm{n}^{\circ} 4.367$, de 9 de setembro de 2002. A referida RIDE abrange os municípios piauienses de Altos, Beneditinos, Coivaras, Curralinhos, Demerval Lobão, José de Freitas, Lagoa Alegre, Lagoa do Piauí, Miguel Leão, Monsenhor Gil, Pau D’Arco, União e Teresina, além do município maranhense de Timon. A Região

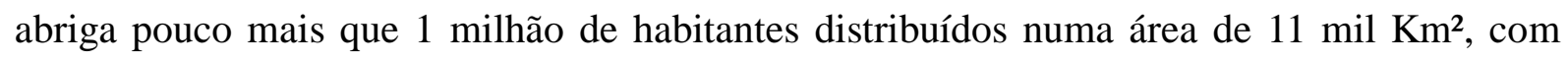
densidade demográfica de 100,53 habitantes/Km² (estimativa 2007 - IBGE). 
Uma particularidade na estruturação da RIDE é que a mesma ultrapassa os limites do estado do Piauí, incorporando o município de Timon, localizado na margem direita do rio Parnaíba, no estado do Maranhão, havendo um processo de conurbação entre as cidades de Teresina e Timon.

Ressaltamos que os estados do Ceará e Maranhão concentram cada estado, duas regiões metropolitanas e os demais estados da macrorregião, com exceção do Piauí que concentra uma RIDE, reúnem apenas uma região metropolitana, tendo estados como Bahia, Rio Grande do Norte e Pernambuco cidades como Feira de Santana, Mossoró e Caruaru, respectivamente, com um grau de modernidade e concentração demográfica que poderiam justificar a formação de arranjos territoriais, a partir desses polos. Destacamos também a Região Integrada de Desenvolvimento Econômico constituída pelos municípios de Lagoa Grande, Orocó, Petrolina, Santa Maria da Boa Vista, no Estado de Pernambuco, e pelos municípios de Casa Nova, Curaçá, Juazeiro e Sobradinho, no Estado da Bahia. No que se refere ao estado da Paraíba, o mesmo concentra doze regiões metropolitanas, sendo o estado com o maior número de regiões metropolitanas instituídas no Brasil, seguido de Alagoas, que concentra nove regiões metropolitanas, pois a Região Metropolitana de Maceió, pioneira nesse processo no que tange essa política institucional no estado, tem sua composição redefinida, ao dividir com outras regiões metropolitanas o espaço territorial alagoano, a exemplo da Região Metropolitana do Agreste instituída em 2009, do Vale do Paraíba e da Zona da Mata em 2011, de Caetés, de Palmeira dos Índios, do São Francisco e do Sertão em 2012, e finalmente do Médio Sertão em 2013.

Essas nove regiões metropolitanas, concentram 88 municípios, dos atuais 102 municípios alagoanos, pois apenas, Maragogi, Japaratinga, Porto de Pedras, São Miguel dos Milagres, Passo de Camaragibe, no litoral norte, Jequiá da Praia no litoral sul, localizados na mesorregião do litoral, São José da Tapera, Monteirópolis, Jacaré dos Homens, Batalha, Belo Monte, Pão de Açúcar, Palestina e Canapi, localizados na mesorregião do sertão, não compõem regiões metropolitanas no estado.

\section{AS REGIÕES METROPOLITANAS DE ALAGOAS}

Nesse constructo introdutório, destacamos que a Região Metropolitana de Maceió (RMM), foi criada pela Lei Complementar $\mathrm{n}^{\circ}$ 18, de 19 de novembro de 1998, tendo, no seu artigo $1^{\circ}$ disposto que, 
A Região Metropolitana de Maceió, é a unidade organizacional, geoeconômica, social e cultural, constituída pelo agrupamento dos municípios de, Barra de Santo Antônio; Barra de São Miguel; Coqueiro Seco; Maceió; Marechal Deodoro; Messias; Paripueira; Pilar; Rio Largo; Santa Luzia do Norte e Satuba, para integrar a organização, o planejamento e a execução de funções públicas de interesse comum.

Difundimos, que a Lei Complementar no 38, datada de 14 de junho de 2013, dispõe sobre a incorporação do Município de Atalaia a Região Metropolitana de Maceió. Difundimos também que a Lei Complementar $n^{0}$ 40, de 17 de junho de 2014, dispõe sobre a incorporação do Município de Murici a Região Metropolitana de Maceió. Sendo assim, os municípios de Atalaia e de Murici, a partir dos anos de 2013 e 2014, respectivamente passam a compor a região metropolitana de Maceió, conforme a tabela 01 e Mapa 01. Destacamos que o município de Murici, compunha originalmente a Região Metropolitana da Zona da Mata e o município de Atalaia, compunha originalmente a Região Metropolitana do Vale do Paraíba.

Tabela 01 - Região Metropolitana de Maceió

\begin{tabular}{|l|l|}
\hline Municípios & $\begin{array}{l}\text { Ano de inserção na } \\
\text { região metropolitana }\end{array}$ \\
\hline Atalaia & 2013 \\
\hline Barra de Santo Antônio & 1998 \\
\hline Barra de São Miguel & 1998 \\
\hline Coqueiro Seco & 1998 \\
\hline Maceió & 1998 \\
\hline Marechal Deodoro & 1998 \\
\hline Messias & 1998 \\
\hline Murici & 2014 \\
\hline Paripueira & 1998 \\
\hline Pilar & 1998 \\
\hline Rio Largo & 1998 \\
\hline Santa Luzia do Norte & 1998 \\
\hline Satuba & 1998 \\
\hline Total de Municípios & 13 \\
\hline
\end{tabular}

Fontes: IBGE, (2010). Lei Complementar N. 18, de 19 de novembro de 1998. Leis Complementares de 2013 e 2014. 
Mapa 01 - Região Metropolitana de Maceió

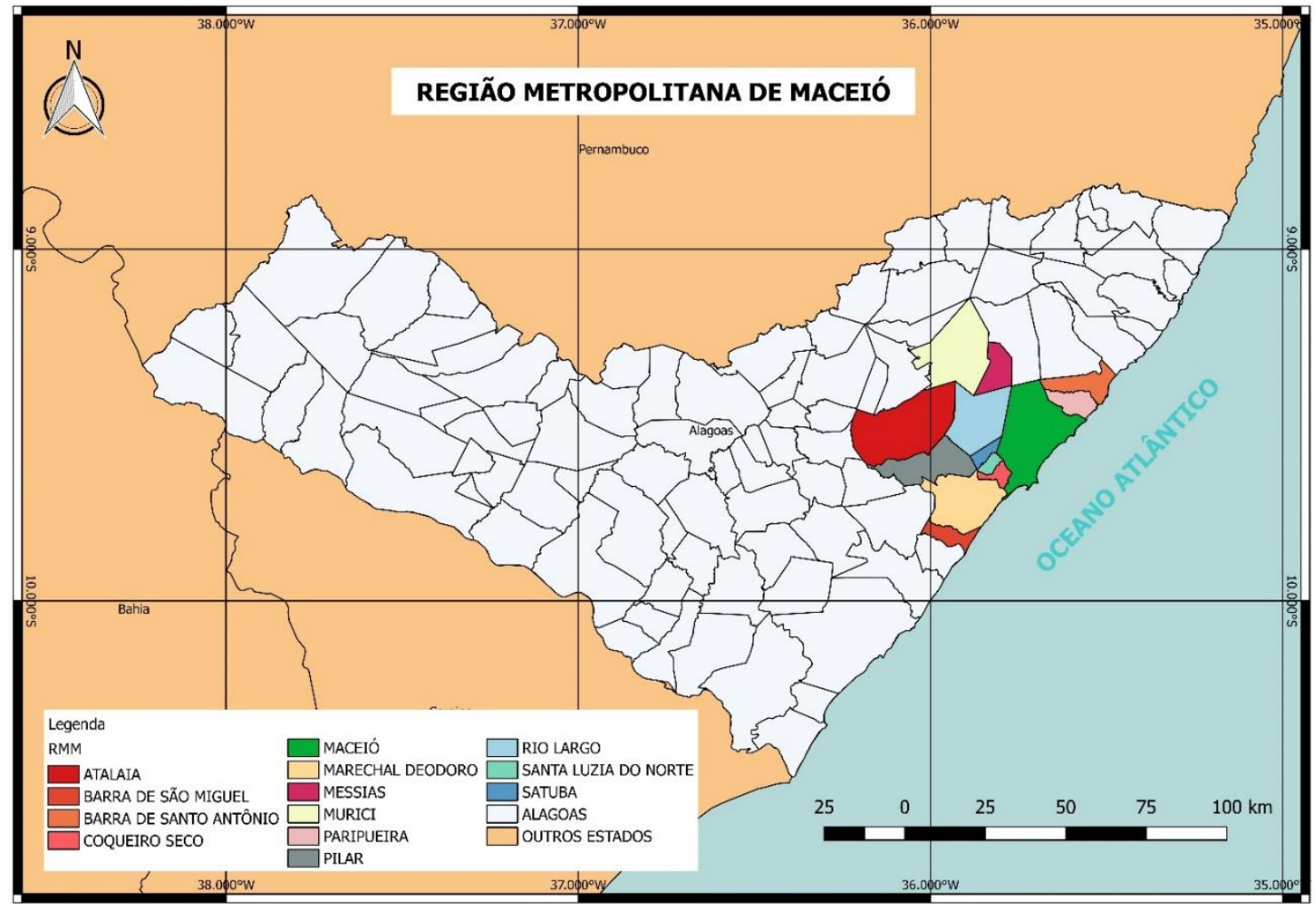

Fonte: FERREIRA, Hermersson Henrique Braz \& SILVA, Paulo Rogério de Freitas. Relatório parcial PIBIC-

UFAL 2016/2017.

No que se refere à região metropolitana do Agreste, criada pela Lei Complementar número 27, de 30 de novembro de 2009, tendo Arapiraca como município polo, esta era composta por vinte municípios elencados na Tabela 02, porem, com a criação das novas regiões metropolitanas, a mesma teve um decréscimo de cinco municípios, passando a ser composta por quinze municípios, conforme podemos visualizar no Mapa 02.

Tabela 02 - Região Metropolitana do Agreste

\begin{tabular}{|l|c|}
\hline Municípios & População \\
\hline Arapiraca & 214.006 \\
\hline Belém & 4.551 \\
\hline Campo Grande & 9.032 \\
\hline Coité do Nóia & 10.926 \\
\hline Craíbas & 22.641 \\
\hline Estrela de Alagoas & 17.251 \\
\hline Feira Grande & 21.321 \\
\hline Girau do Ponciano & 36.600 \\
\hline Igaci & 25.188 \\
\hline Jaramataia & 5.558 \\
\hline
\end{tabular}


Revista de Geografia (Recife) V. 34, No. 2, 2017

\begin{tabular}{|l|c|}
\hline Junqueiro & 23.836 \\
\hline Lagoa da Canoa & 18.250 \\
\hline Limoeiro de Anadia & 26.992 \\
\hline Olho d'Água Grande & 4.957 \\
\hline Palmeira dos Índios & 70.368 \\
\hline São Brás & 6.718 \\
\hline São Sebastião & 32.010 \\
\hline Tanque d'Arca & 6.122 \\
\hline Taquarana & 19.020 \\
\hline Traipu & 25.702 \\
\hline Total & 601.049 \\
\hline
\end{tabular}

Fonte: Censo Demográfico do IBGE (2010)

Os municípios de Palmeira dos Índios, Igaci, Estrela de Alagoas e Belém, passaram a compor a Região Metropolitana de Palmeira dos Índios, instituída em 2012 e o município de Tanque D’Arca passou a compor a Região Metropolitana do Vale do Paraíba, instituída em 2011.

Mapa 02 - Região Metropolitana do Agreste.

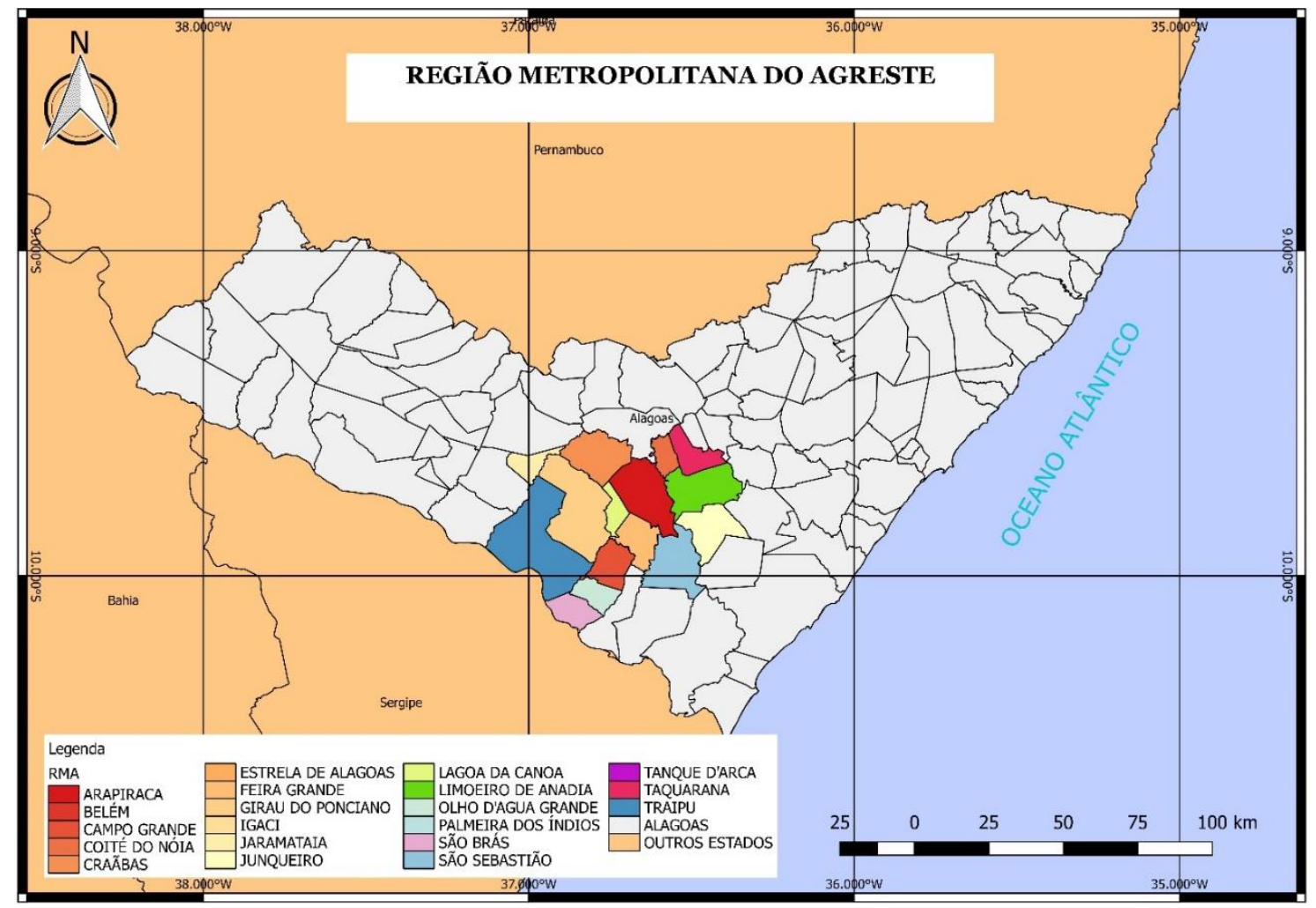

Fonte: FERREIRA, Hermersson Henrique Braz \& SILVA, Paulo Rogério de Freitas. Relatório parcial PIBICUFAL 2016/2017. 
Sendo assim, a Região Metropolitana do Vale do Paraíba, instituída em 2011, é composta pelos municípios de Capela, Cajueiro, Viçosa, Mar Vermelho, Chã Preta, Paulo Jacinto, Quebrangulo, Maribondo, Anadia, Tanque D'Arca, Boca da Mata e Pindoba. A Região Metropolitana da Zona da Mata, instituída em 2011, é composta pelos seguintes municípios, Branquinha, Campestre, Colônia Leopoldina, Flexeiras, Jacuípe, Joaquim Gomes, Jundiá, Matriz de Camaragibe, Novo Lino, Porto Calvo, São Luiz do Quitunde, União dos Palmares, São José da Laje, Santana do Mundaú e Ibateguara. A Região Metropolitana de Palmeira dos Índios, instituída em 2012, é composta pelo município que a denomina, seguido de Igaci, Estrela de Alagoas, Cacimbinhas, Minador do Negrão, Belém e Major Isidoro. A Região Metropolitana do São Francisco é composta por Penedo, Piaçabuçu, Feliz Deserto, Igreja Nova e Porto Real do Colégio. A Região Metropolitana dos Caetés, instituída em 2012, é organizada pelos municípios de São Miguel dos Campos, Teotônio Vilela, Campo Alegre, Coruripe e Roteiro. A Região Metropolitana do Sertão, instituída em 2012, tem em sua composição os municípios de Delmiro Gouveia, Pariconha, Água Branca, Olho D’Água do Casado, Piranhas, Mata Grande e Inhapi e, a Região Metropolitana do Médio Sertão instituída em 2013, compreende, Santana do Ipanema, Dois Riachos, Olivença, Olho D’Água das Flores, Carneiros, Senador Rui Palmeira, Poço das Trincheiras, Maravilha e Ouro Branco. Destacamos novamente, que apenas, Maragogi, Japaratinga, Porto de Pedras, São Miguel dos Milagres, Passo de Camaragibe, no litoral norte, Jequiá da Praia no litoral sul, localizados na mesorregião do litoral, São José da Tapera, Monteirópolis, Jacaré dos Homens, Batalha, Belo Monte, Pão de Açúcar, Palestina e Canapi, localizados na mesorregião do sertão, não compõem regiões metropolitanas no estado, conforme Mapa 03.

Detalhando as Leis Complementares que criam as duas pioneiras regiões metropolitanas nas Alagoas, destacamos que, a Lei Complementar que cria a RMM - Região Metropolitana de Maceió é composta por catorze artigos, considerando no seu artigo 1 que a mesma é uma unidade organizacional, geoeconômica, social e cultural; mostra que é composta por um agrupamento de municípios, citando-os e destaca que busca integrar a organização, o planejamento e a execução de funções públicas de interesse comum. A Lei complementar que cria a RMA Região Metropolitana do Agreste é composta por nove artigos, sendo que no seu artigo primeiro, também demonstra que é constituída pelo agrupamento de municípios, buscando integrar a organização, o planejamento e a execução de funções públicas de interesse comum. 
No artigo 2, as duas leis complementares tratam dos requisitos básicos para que essas regiões metropolitanas sejam ampliadas, considerando para a RMM a evidência ou tendência de conurbação e para a RMA apenas tendência de conurbação; para as duas são consideradas a necessidade de organização, planejamento e execução de funções públicas de interesse comum; existência de relação de integração funcional de natureza socioeconômica ou de serviços. Nesse artigo é que a Lei que cria a RMA destaca que a mesma é uma unidade organizacional, geoeconômica, social e cultura.

O artigo 3, da Lei que se refere a RMM versa nos números I, II, III e IV de conceitos, no número $\mathrm{V}$ trata do mesmo tema que o artigo 3 da Lei que cria a RMA aborda, ao se referir, as funções públicas de interesse comum. Ambas se remetem ao planejamento, em nível global ou setorial de questões territoriais, ambientais, econômicas, culturais, sociais e institucionais; a execução de obras e implantação, operação e manutenção de serviços públicos e; supervisão, controle e avaliação da eficácia da ação pública metropolitana. Na lei que trata especificamente da criação da RMM trata de financiamento da implantação, operação e manutenção de obras e serviços, e também sua remuneração e recuperação de custos, que não é abordado na Lei que cria a RMA. 


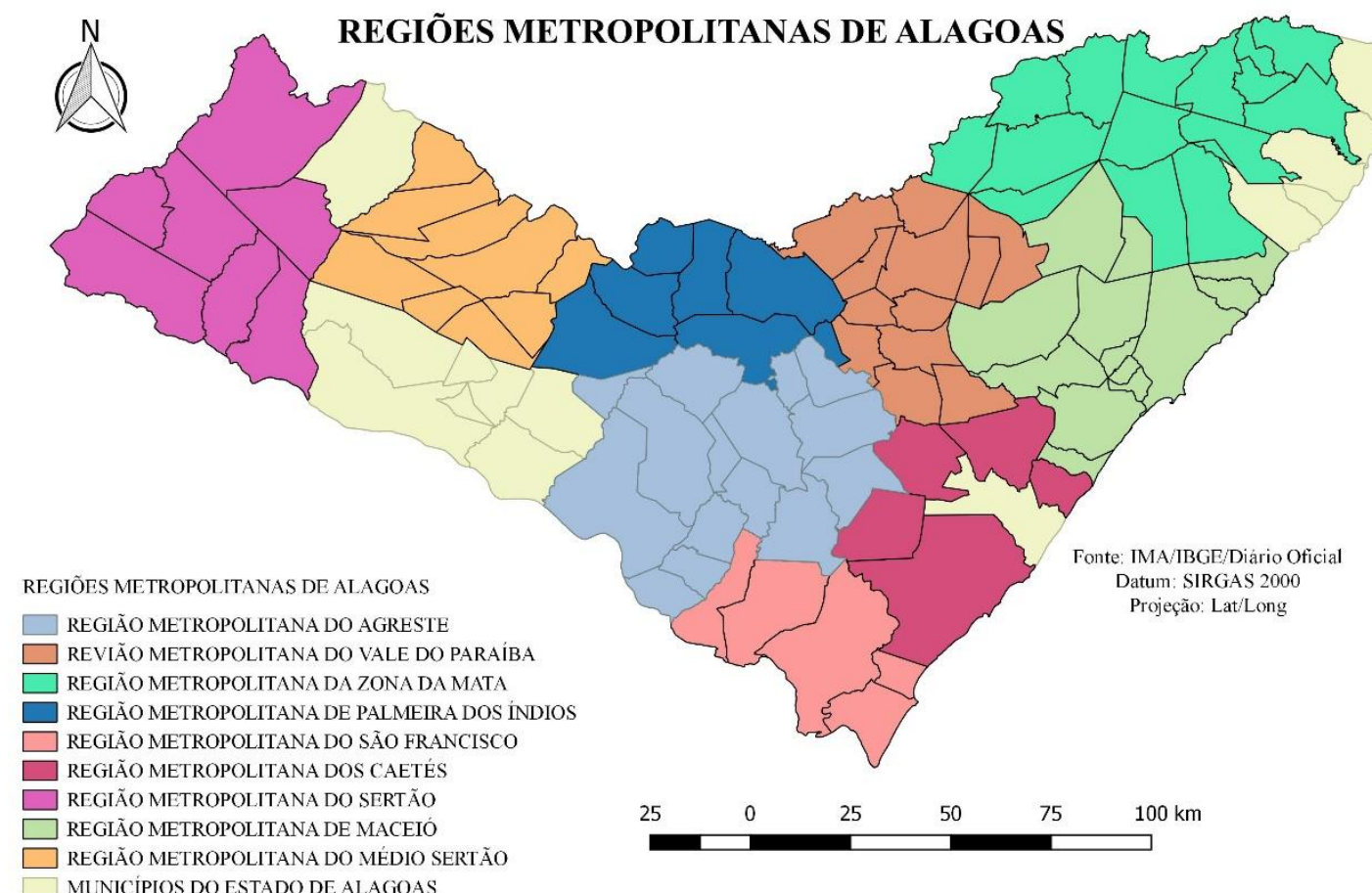

Fonte: FERREIRA, Hermersson Henrique Braz \& SILVA, Paulo Rogério de Freitas. Relatório parcial PIBICUFAL 2016/2017.

O artigo 4, trata nas duas Leis, da execução dos serviços públicos, sendo que, na Lei que trata da RMM a execução dos serviços ocorre quando for interesse comum no âmbito metropolitano e será de forma compartilhada pelos Municípios e pelo Estado, observando-se critérios de parcerias definidos pelo órgão deliberativo do Sistema Gestor Metropolitano SGM. A Lei que cria a RMA destaca que a execução dos serviços ocorre quando de interesse comum de dois ou mais municípios integrantes da região metropolitana. A execução será de forma compartilhada pelos Municípios com interveniência/cooperação do Estado.

O artigo 5 da Lei que trata da RMM, instituí o SGM - Sistema Gestor Metropolitano e na Lei que trata da criação da RMA cria o CRMA - Conselho de Desenvolvimento e Integração da Região Metropolitana do Agreste.

O artigo 6 na Lei que cria a RMM, enfatiza o que os agentes envolvidos no exercício das funções públicas de interesse comum no âmbito metropolitano devem adotar permanentemente. No que se refere à Lei que trata da RMA, a mesma no artigo 5 trata da composição do CRMA. 
O artigo 7 da Lei que trata da criação da RMM, demonstra quais os instrumentos que serão utilizados para o planejamento e a gestão metropolitana; na Lei que trata da RMA é destacado que o poder executivo regulamentará as matérias de que trata esta Lei Complementar, mediante a expedição das normas necessárias ao seu fiel cumprimento.

O artigo 8 da Lei que cria a RMM versa sobre como será constituído o CDM Conselho de Desenvolvimento Metropolitano e; na Lei que trata da criação da RMA apenas destaca a data que a Lei entrará em vigor.

O artigo 9 que trata da RMM destaca como o CDM será apoiado nas suas deliberações e; na Lei da RMA apenas revoga a Lei de criação da referida região metropolitana.

Os artigos 10, 11, 12, 13 e 14 competem apenas a Lei que cria a RMM, tratando, respectivamente, do que compete a secretaria executiva da RM; do Fundo de Desenvolvimento da Região Metropolitana de Maceió - FUNDERM; do que se poderão constituir receitas do FUNDERM; da regulamentação da Lei e; da entrada em vigor da Lei..

\section{EM BUSCA DE ANOTAÇÕES CONCLUSIVAS}

A apreciação efetuada revela os debates e nos entusiasma a prosseguir essa jornada, demandando novas discussões sobre a institucionalização das regiões metropolitanas no estado das Alagoas, devido às demandas que brotaram, principalmente a partir da institucionalização de sete novas regiões metropolitanas no estado entre 2011 e 2013 e as alterações nas composições das mesmas em 2013 e 2014.

Ponderamos que a institucionalização das regiões metropolitanas de Alagoas, incide a partir da decretação de Leis Complementares, estruturadas por artigos que as regulamentam, de acordo com os interesses do Estado, conforme delibera a Constituição Brasileira de 1988, que passou para os Estados a competência de criação de novas regiões metropolitanas no Brasil com o argumento da descentralização administrativa.

Por outro lado, o Estatuto da Metrópole instituído em 2015, estabelece diretrizes gerais para o planejamento, a gestão e a execução das funções públicas de interesse comum nas regiões metropolitanas e nas aglomerações urbanas instituídas por esses Estados.

E ao geógrafo, conforme destaca Silva (2010), compete perguntar se a cidade termina nos seus limites ou se ela é contínua, analisando e propondo estudos que apreenda as relações entre o rural e o urbano, entre a cidade e a região, entre a cidade e as diversas redes que se 
estabelecem. E a esse ponto, sobrepomos a necessidade de analisar as relações entre os municípios, que acomodam essas cidades e vilas ou outros tipos de aglomerados.

No que se refere às Leis Complementares que instituem as regiões metropolitanas, destacamos que a composição das mesmas por um agrupamento de municípios, buscando integrar a organização, o planejamento e a execução de funções públicas de interesse comum, ratifica um possível empenho político numa escala local, buscando a formalização de artifícios que agreguem os municípios das regiões, sem evidências que possam motivar a formação das mesmas de acordo com o seu raio de influência regional ou nacional. Simula uma rede urbana, que, "em termos genéricos constitui-se no conjunto de centros urbanos funcionalmente articulados entre si. (...) no qual os vértices ou nós são os diferentes núcleos de povoamento dotados de funções urbanas, e os caminhos ou ligações os diversos fluxos entre esses centros, conforme (CORRÊA, 2001). Acrescentamos que poderíamos tratar como uma rede urbana dendrítica, caracterizada, entre outros aspectos, pela presença de uma cidade primaz excentricamente localizada, de acordo com (CORRÊA, 2006), justificando assim, essa organização regional ou esse arranjo.

Então, baseados em Lencioni (2006), essas regiões metropolitanas são formadas por um conjunto de municípios que detêm um nó significativo de redes, sejam de transporte, informação, comunicação, cultura, inovação, consumo, poder ou, mesmo, de cidades. Porém, a forma urbana de tamanho expressivo, quer relativo ao número de sua população, quer em relação à sua extensão territorial; as diversas atividades econômicas, destacando-se a concentração de serviços de ordem superior; o ser um locus privilegiado de inovação e; serem emissores e receptores dos fluxos de informação e comunicação, não são considerados na argumentação de se criarem essas regiões em Alagoas.

Ao tratarem de conurbação, que poderia ser um processo indutor para a instauração de um planejamento conjunto entre municípios, já que trataria do encontro de manchas urbanas de suas cidades sedes ou de suas vilas, apenas cita esse processo como capaz de conduzir a ampliação das regiões metropolitanas, quando se apresentarem, através de evidencia ou tendência. Notamos também que as funções públicas de interesse comum entre os municípios que compõem essas regiões metropolitanas em foco almejam igualmente um planejamento, em nível global ou setorial de questões territoriais, ambientais, econômicas, culturais, sociais e institucionais; a execução de obras e implantação, operação e manutenção de serviços públicos e; a supervisão, controle e avaliação da eficácia da ação pública metropolitana, conduzido por um sistema gestor e por um conselho de desenvolvimento e integração, 
utilizando recursos de um fundo de desenvolvimento, como cita o artigo 11 que trata da criação da região metropolitana de Maceió. Então se busca uma forma de administrar o conjunto de municípios, sem considerar a diferença na aplicação dos conceitos de metrópole, região metropolitana e aglomeração urbana.

A partir dessas Leis Complementares, cremos que as regiões metropolitanas das Alagoas, são criadas e instituídas na procura de um planejamento conjunto que ainda não foi devidamente definido pelos seus idealizadores, ou que possivelmente estejam sendo impelidos a seguirem um modelo ou uma voga de concepção de regiões metropolitanas do Brasil.

É preciso evidenciar diferenças estruturais existentes entre as regiões metropolitanas instituídas em Alagoas que possibilite uma amostragem distinta entre as mesmas. A conurbação em processo de constituição, a condição de capital de estado e de centro comercial e centro prestador de serviços, são aspectos que particularizam a Região Metropolitana de Maceió em detrimento da composição das demais regiões metropolitanas, a exemplo da Região Metropolitana do Agreste constituídas por quinze municípios, satélites de Arapiraca, que apresenta uma complexidade e uma área de influência de alcance local.

Por exemplo, o Estatuto da Metrópole, ao conceituar aglomeração urbana se refere a uma unidade territorial urbana constituída pelo agrupamento de 2 (dois) ou mais Municípios limítrofes, caracterizados por complementaridade funcional e integração das dinâmicas geográficas, ambientais, políticas e socioeconômicas, se distinguindo do que o mesmo define como metrópole no que se refere à influência regional ou nacional, que a metrópole alcança, aspecto principal na distinção entre os dois conceitos apresentados. Dessa forma, constatamos que o que se institui como região metropolitana do Agreste, na perspectiva do Estatuto da Metrópole, se constitui, como uma aglomeração urbana e não como uma região metropolitana, pois a mesma se organiza por um agrupamento de municípios com complementaridade funcional e integração, mas, de alcance local.

$\mathrm{Na}$ perspectiva da ciência geográfica, Souza (2003) define que uma aglomeração urbana se forma quando duas ou mais cidades passam a atuar como um minissistema urbano destacando que é importante que nenhuma das cidades envolvidas possa ser muito grande, a ponto de satelitizar completamente as demais a sua volta e possuir uma área de influência regional. $\mathrm{O}$ autor assinala que se uma das cidades que formam uma aglomeração urbana crescer e se destacar demais, apresentando-se como uma cidade grande e com uma área de 
influência econômica, pelo menos regional, então não se está mais diante de uma simples aglomeração, mas de uma metrópole.

Então, considerando o ponto de vista de Souza (2003), destacamos que Arapiraca se destaca demograficamente, conforme a tabela 02 , se sobressaindo em relação aos demais municípios que compõem essa aglomeração urbana. Porém, ao nos reportarmos a esse arranjo no que se refere ao seu raio de influência, o mesmo por ter um alcance local, isto é, entre os seus municípios, com exceções de alcance estadual, se caracteriza como uma aglomeração urbana e não como uma região metropolitana, que deve ter um raio de influência regional ou nacional análogo ao que define o Estatuto da Metrópole.

Destacamos que se as iniciativas de estabeleceram status as regionalizações aqui em foco, ocorrerem buscando apenas transferências de recursos financeiros o artigo 15 do Estatuto da Metrópole assim se reporta a questão:

A região metropolitana instituída mediante lei complementar estadual que não atenda o disposto no inciso VII do caput do art. $2^{\circ}$ desta Lei, será enquadrada como aglomeração urbana para efeito das políticas públicas a cargo do Governo Federal, independentemente de as ações nesse sentido envolverem ou não transferência de recursos financeiros.

Em seguida, ao nos debruçarmos para entender a instituída região metropolitana de Maceió, partimos do Estatuto da Metrópole, que ao conceituar metrópole como um espaço urbano com continuidade territorial que tem influência nacional ou sobre uma região, em razão de sua população e de sua relevância política e socioeconômica, tendo um alcance mínimo de uma capital regional, pode agraciar a região metropolitana de Maceió com essa condição já que, define região metropolitana como uma aglomeração urbana que se configura como uma metrópole, tendo influência de uma capital regional, tal como define o inciso $\mathrm{V}$ ao se referir à metrópole.

O artigo VII se refere à região metropolitana como uma aglomeração urbana que configure uma metrópole e em seu parágrafo único afirma que:

Os critérios para a delimitação de uma região de influência de uma capital regional, previsto no inciso $\mathrm{V}$ do caput deste artigo considerarão os bens e serviços fornecidos pela cidade à região, abrangendo produtos industriais, educação, saúde, serviços bancários, comércio, empregos e outros itens pertinentes, (...).

Baseados no Site do IBGE, observamos que Maceió, fornece esses bens e serviços à região, considerando às instituições financeiras com 73 agências bancárias, estabelecimento 
de saúde com atendimentos de emergência, ambulatorial, diagnose e de internação que atende todo o estado de Alagoas, concentrando também instituições de ensino de nível, fundamental, médio e superior, com cursos de pós-graduação em instituições públicas e privadas.

O uso da categoria região metropolitana para Maceió pode se justificar ao dialogarmos com Lencioni (2006), quando a autora se refere à questão em discussão, inclusive utilizando Maceió como exemplo:

A condição de capital cria maiores possibilidades de as metrópoles consolidarem o processo de metropolização que vem ocorrendo, pois, como capitais, polarizam a aglomeração urbana, constituindo nó importante de redes, bem como concentrando toda sorte de serviços mais avançados e de serviços públicos importantes para o capital, e, também, os fluxos de informação, comunicação e as universidades. É o caso de Natal, São Luiz e Maceió, no Norte; Grande Vitória no Sudeste; Goiânia e Brasília no Centro-Oeste, e Florianópolis, no Sul.

Destacamos que Maceió é polo atrativo, tanto como centro comercial, como também como centro prestador de serviços, em especial na área de saúde e educação. Tal fato gera fluxo de pessoas, como também uma convergência de interesses políticos-institucionais dos municípios que compõem a região metropolitana e o estado de Alagoas. Projetos rodoviários para melhor integrar essas unidades municipais já é uma necessidade premente, o que torna possíveis ações integradoras em lógica metropolitana. Vários outros setores possuem o mesmo nexo, como o da hortifruticultura, do turismo de eventos, da educação e da segurança. O Plano Diretor de Maceió, já define pontos a serem postos em prática dentro do alcance da região metropolitana, em destaque para o turismo.

A materialização da conurbação entre os centros urbanos que compõem os municípios de Maceió, Paripueira, Rio Largo, Marechal Deodoro e com princípio de formação entre outros, formalizam eixos de transportes coletivos, favorecendo a mobilidade entre esses lugares, no que se refere ao movimento casa-trabalho, dinamizando a economia local e transformando alguns lugares em cidades-dormitórios devido à concentração das atividades na cidade de Maceió.

Porém, entre os pontos analisados e expostos ao longo desse texto, que procurou sistematizar as regiões metropolitanas alagoanas, como uma proposta pautada num planejamento, por parte do Estado, que visa à melhoria da qualidade de vida da população local, evidenciamos, a partir do ponto de vista de Souza (2008), que a “(...) a metrópole [é] essencialmente o lugar da pobreza." E que região, “(...) é um instrumento ideológico e 
político, é mutável, é instrumento para ação e tem relação com processos amplos de urbanização e metropolização" (SOUZA 2006).

Então, se Souza (2006) e (2008), propõe essa reflexão, por que instituir regiões metropolitanas em Alagoas e qual o caráter prático que essa regionalização proporciona? Esses são temas caros possíveis de serem encaminhados já que, Souza (2006), ao se referir à regionalização no Brasil, destaca que historicamente a mesma:

(...) é para permitir a fluidez - para permitir que os fluxos se realizem, e não os fixos. Nos fixos está a população, o povo, que nunca resolve plenamente seus problemas. Eu estudo isso há muito tempo e fico preocupada com as regiões metropolitanas. Elas contribuíram para o elo da lógica capitalista, por meio das políticas.

Sendo assim, esse é o princípio de um estudo mais amplo na busca de entender o significado e os objetivos das regiões metropolitanas de Alagoas: Maceió institucionalizada em 1998, Agreste em 2009, Vale do Paraíba e da Zona da Mata em 2011, de Caetés, de Palmeira dos Índios, do São Francisco e do Sertão em 2012, e finalmente do Médio Sertão em 2013.

\section{REFERÊNCIAS}

\section{ALAGOAS. Alagoas em Mapas [material cartográfico]: acervo de mapas sobre o Estado}

de Alagoas / Secretaria de Estado do Planejamento e do Desenvolvimento Econômico. - 1. ed. - Maceió: SEPLANDE, 2012.

ALAGOAS. Lei Complementar n 27, de 30 de novembro de 2009 (Criação da Região Metropolitana do Agreste).

ALAGOAS. Lei Complementar nº 18, de 19 de novembro de 1998 (Criação da Região Metropolitana de Maceió).

BARRETO, Ilson Juliano. O surgimento de novas regiões metropolitanas no Brasil: uma discussão a respeito do caso de Sorocaba (SP). Espaço e Economia: Revista Brasileira de Geografia Econômica. 1 (2012): ano 1, Número 1. (online).

BRASIL. Estatuto da Metrópole. Lei no 13.089 de 12 de janeiro de 2015.

CORRÊA. Roberto Lobato. Estudos sobre a rede urbana. Rio de Janeiro: Bertrand Brasil, 2006.

Trajetórias Geográficas. Rio de Janeiro: Bertrand Brasil, 2001. 
COSTA, Rogério Haesbaert. Regional-Global: dilemas da região e da regionalização na geografia contemporânea. Rio de Janeiro: Bertrand Brasil, 2010.

FERREIRA, Hermersson Henrique Braz \& SILVA, Paulo Rogério de Freitas Silva. Relatório parcial PIBIC-UFAL 2016/2017 - A institucionalização das regiões metropolitanas das Alagoas: o desafio do planejamento regional. O significado das regiões metropolitanas de Maceió e do Agreste no contexto estadual alagoano.

FUNDAÇÃO INSTITUTO BRASILEIRO DE GEOGRAFIA E ESTATÍSTICA - IBGE. Censo Demográfico. Rio de Janeiro, 2010.

FUNDAÇÃO INSTITUTO BRASILEIRO DE GEOGRAFIA E ESTATÍSTICA - IBGE. Censo Demográfico. Rio de Janeiro, 2000.

GOMES, Paulo Cesar da Costa. O conceito de região e sua discussão. In: Geografia: conceitos e temas. Org. Iná Elias de Castro, Paulo Cesar da Costa Gomes, Roberto Lobato Corrêa. $7^{\mathrm{a}}$ ed. Rio de Janeiro: Bertrand Brasil, 2005.

GONÇALVES, Maria Flora; BRANDÃo Carlos Antônio; GALVÃO, Antônio Carlos (Org.). Regiões e cidades, cidades nas regiões: o desafio urbano regional. São Paulo: Editora UNESP: ANPUR, 2003.

IBAM - Instituto Brasileiro de Administração Municipal e DES - Área de Desenvolvimento Econômico e Social. Proposta de Modelo de Regionalização. Elaboração do modelo de regionalização para o planejamento do Estado de Alagoas. Junho de 2013.

LENCIONI, Sandra. Reconhecendo metrópoles: território e sociedade. In: Metrópole: Governo, sociedade e território. Catia Antonia da Silva, Desirée Guichard Freire e Floriano José Godinho de Oliveira (organizadores). Rio de Janeiro: DP\&A: Faperj, 2006.

MORAES, Antônio Carlos Robert de. Notas metodológicas sobre metropolização e a metrópole. In: Geografia das metrópoles/ Ariovaldo Umbelino de Oliveira, Ana Fani Alessandri Carlos, (organizadores). - São Paulo: Contexto, 2006.

RODRIGUES, Arlete Moysés. Gestão da região metropolitana e da metrópole: possibilidades e limites de gestão compartilhada. In: Geografia das metrópoles/ Ariovaldo Umbelino de Oliveira, Ana Fani Alessandri Carlos, (organizadores). - São Paulo: Contexto, 2006.

SILVA, José Borzacchiello da. Geografia Urbana - uma agenda nacional. CIDADES: Revista Científica / Grupo de Estudos Urbanos - vol. 7, n. 12, 2010- Presidente Prudente: Grupo de Estudos Urbanos, 2010.

SOUZA, Marcelo Lopes de. ABC do Desenvolvimento Urbano. Rio de Janeiro: Bertrand Brasil, 2003. 
SOUZA, Maria Adélia Aparecida de. A Metrópole e o Futuro: a dinâmica dos lugares e o período popular da história. In: A Metrópole e o Futuro: Refletindo sobre Campinas. Maria Adélia Aparecida de Souza (organizadora). Campinas: Edições TERRITORIAL, 2008.

Recompondo a história da região metropolitana: processo, teoria e ação. In: Metrópole: Governo, sociedade e território. Catia Antonia da Silva, Desirée Guichard Freire e Floriano José Godinho de Oliveira (organizadores). Rio de Janeiro: DP\&A: Faperj, 2006.

VILLAÇA, Flávio. Um ângulo de síntese: a análise do espaço. In: Regiões e cidades, cidades nas regiões: o desafio urbano regional. Org. Maria Flora Gonçalves, Carlos Antônio Brandão, Antônio Carlos Galvão. São Paulo: Editora UNESP: ANPUR, 2003. 